\title{
Article
}

\section{Disease-Free Survival after Breast Conservation Therapy vs. Mastectomy of Patients with T1/2 Breast Cancer and No Lymph Node Metastases: Our Experience}

\author{
Annarita Fanizzi ${ }^{1}$, Maurizio Cosmo Ressa ${ }^{2}$, Gianluca Gatta ${ }^{3}\left(\mathbb{D}\right.$, Cristian Cristofaro $^{1}$, Valerio De Santis ${ }^{2}$, \\ Vittorio Didonna ${ }^{1}\left({ }^{\circ}\right.$, Sergio Diotaiuti ${ }^{4}$, Daniele La Forgia ${ }^{5, *}{ }^{\circ}$, Nicole Petruzzellis ${ }^{1}$, Pasquale Tamborra ${ }^{1}$, \\ Vito Lorusso ${ }^{6}$ and Raffaella Massafra ${ }^{1}$
}

Citation: Fanizzi, A.; Ressa, M.C.; Gatta, G.; Cristofaro, C.; De Santis, V.; Didonna, V.; Diotaiuti, S.; Forgia, D.L.; Petruzzellis, N.; Tamborra, P.; et al. Disease-Free Survival after Breast

\section{Conservation Therapy vs.}

Mastectomy of Patients with T1/2 Breast Cancer and No Lymph Node Metastases: Our Experience. Appl. Sci. 2021, 11, 9800. https://doi.org/ 10.3390/app11219800

Academic Editor: Ibrahim M. Banat

Received: 29 July 2021

Accepted: 16 October 2021

Published: 20 October 2021

Publisher's Note: MDPI stays neutral with regard to jurisdictional claims in published maps and institutional affiliations.

Copyright: (C) 2021 by the authors Licensee MDPI, Basel, Switzerland. This article is an open access article distributed under the terms and conditions of the Creative Commons Attribution (CC BY) license (https:/ / creativecommons.org/licenses/by/ $4.0 /)$.
1 Struttura Semplice Dipartimentale di Fisica Sanitaria, I.R.C.C.S. Istituto Tumori "Giovanni Paolo II", Viale Orazio Flacco 65, 70124 Bari, Italy; a.fanizzi@oncologico.bari.it (A.F.); c.cristofaro@oncologico.bari.it (C.C.); v.didonna@oncologico.bari.it (V.D.); nicole.petruzzellis2@gmail.com (N.P.); p.tamborra@oncologico.bari.it (P.T.); r.massafra@oncologico.bari.it (R.M.)

2 Unità Operativa Complessa di Chirurgica Plastica e Ricostruttiva, I.R.C.C.S. Istituto Tumori "Giovanni Paolo II", Viale Orazio Flacco 65, 70124 Bari, Italy; m.ressa@oncologico.bari.it (M.C.R.); v.desantis@oncologico.bari.it (V.D.S.)

3 Dipartimento di Medicina di Precisione, Università della Campania "Luigi Vanvitelli", 80127 Napoli, Italy; gianluca.gatta@unicampania.it

4 Struttura Semplice Dipartimentale di Chirurgia, I.R.C.C.S. Istituto Tumori "Giovanni Paolo II", Viale Orazio Flacco 65, 70124 Bari, Italy; sergiodiotaiuti@gmail.com

5 Struttura Semplice Dipartimentale di Radiologia Senologica, I.R.C.C.S. Istituto Tumori "Giovanni Paolo II", Viale Orazio Flacco 65, 70124 Bari, Italy

6 Unità Operativa Complessa di Oncologia Medica, I.R.C.C.S. Istituto Tumori "Giovanni Paolo II", Viale Orazio Flacco 65, 70124 Bari, Italy; vitolorusso@me.com

* Correspondence: d.laforgia@oncologico.bari.it; Tel.: +39-080-555-5111

\begin{abstract}
Several retrospective analyses of large amounts of contemporary data have shown the superiority of breast conservative surgery (BCS) over mastectomy carried out in the early stage of breast cancer. The characteristics of the patients and cancers that are most likely to benefit from BCS remain unclear. In our work, we analyzed the disease-free survival (DFS) of a cohort of patients treated with BCS or mastectomy between 1995 and 2018 in our institute with pT1-2, pN0, or cM0 breast cancer. The DFS curves of patients treated with both mastectomy and quadrantectomy were compared in the different subsamples with respect to the clinical and histopathological characteristics. We identified 188 eligible patients treated with BCS and 64 patients treated with mastectomy. DFS was not found to be statistically higher in patients treated with BCS compared to those treated with mastectomy, who achieved a 5 -year DFS of $89.9 \%$ vs. $81.3 \%$ and a 10 -year DFS of $78.9 \%$ vs. $79.3 \%$, respectively. No significant differences were detected for the DFS curves when patients were differentiated by the type of surgical treatment received, age, and the tumor histological characteristics. We verified a $p$-value just above the $10 \%$ significance threshold for patients with tumor dimensions between $20 \mathrm{~mm}$ and $50 \mathrm{~mm}$ and molecular sub-type Luminal B. In our experience, treatment with mastectomy is not associated with improved DFS compared to treatment with BCS in women with early-stage tumors.
\end{abstract}

Keywords: conservative breast surgery; mastectomy; quadrantectomy; breast cancer disease-free survival; early stage cancers; T1-2 tumors; N0 tumors

\section{Introduction}

Breast cancer surgery has undergone profound changes in the last few decades [1,2]. Breast conservative surgery (quadrantectomy, BCS) and the adoption of new techniques for "conservative" mastectomy (skin-sparing and nipple-sparing) are clear examples of oncological surgery aimed at improving the patient's aesthetics and quality of life. 
The most important studies that showed a substantial equivalence between BCS plus adjuvant radiotherapy of the entire breast and mastectomy were conducted some decades ago $[3,4]$. Their conclusions were crucial in changing the approach to local breast cancer treatment. Nevertheless, the scenario today has substantially changed. Nowadays, in this context, the preservation of the mammary organ by BCS has become the treatment of choice, thanks to the excellent results and optimal tolerability achieved [5,6]. However, various population-based studies have shown that mastectomy is still considered a reliable treatment option chosen by some breast cancer patients in daily clinical practice. The breast cancer survival rates are now higher. This is probably due to several factors, such as the smaller tumor dimensions, fewer patients with positive lymph nodes at diagnosis, as well as the more effective therapies available, including neoadjuvant therapies based on specific neoplastic characteristics $[7,8]$.

In recent years, several retrospective analyses of large contemporary datasets have shown the superiority of treatment with BCS over treatment with mastectomy in the early stages of breast cancer. BCS was found to provide better outcomes than mastectomy for eligible patients with stage I breast cancer, in terms of specific survival and overall survival, and thus should be offered as a preferred treatment option [9-11]. Moreover, other studies focused on young women [12,13] and on triple-negative breast cancer $[14,15]$ have shown similar results.

In some studies, locoregional recurrence percentages have been found to be higher after BCS than after mastectomy [16]. This has been further confirmed in triple-negative breast cancer and positive receptor 2 of the human epidermal growth factor (HER2) [15], even though Zumsteg et al. reported contradictory results [14]. Unfortunately, the locoregional recurrence percentages were rarely provided in the cited retrospective analyses, as the data were not always reliable. Therefore, the presumed superiority of mastectomy over BCS in reducing locoregional recurrence has not been clearly shown. Moreover, the subgroup of patients that could benefit from BCS remains unclear.

In this paper, we analyzed the disease-free survival of the patients treated in our institute, differentiating between patients who received breast conservative therapy and patients who received mastectomy. We studied evidence gathered for different subgroups of patients treated at our institute in the last 20 years.

\section{Materials and Methods}

\subsection{Experimental Data}

For this study, we considered women referred to the I.R.C.C.S. "Giovanni Paolo II" Cancer Institute (Bari, Italy) from 1995 to 2018. We collected data from 250 patients according to the following inclusion criteria: (i) female gender (ii) histologically confirmed invasive breast carcinoma; (iii) no metastatic ab initio cancer (pM0); (iv) negative lymph node status (pN0); (v) pT1-2 tumor size; (vi) patients who had received prophylactic mastectomy.

A clinically node-negative axilla was defined as no palpable lesion to suggest the spread of disease to the axilla and those who did not have suspicious signs in an axillary ultrasound.

Women who underwent mastectomy with T1-2 N0 stage did not receive adjuvant radiotherapy. On the contrary, women who underwent quadrantectomy received adjuvant radiotherapy on the remaining breast regardless of their stage [17].

This study was approved by the scientific board of our institute and carried out in the manner prescribed by the Helsinki declaration. All patients who gave consent to use the data for scientific purposes were recruited.

Several histological outcomes were recorded, including tumor size, tumor type, tumor grade G, multifocality/multicentricity, concomitant ductal carcinoma in situ (DCIS), estrogen receptor (ER) status, progesterone receptor (PR) status, human epidermal growth factor (HER2) status, Ki-67, the presence of lymphovascular invasion, and type of breast surgical procedure. Histological analyses were performed by the pathology department of our institute. 
The expressions of ER, PR, and Ki-67 antigens associated with cell proliferation were valued in percentage terms. A cut off value of $20 \%$ positive cells was used to indicate tumors that were highly proliferating. HER2 status was considered to be positive if immunostaining was $3+$ or if a score of $2+$ showed gene amplification using fluorescence in situ hybridization (FISH).

The tumor histological grade $\mathrm{G}$ was defined by the Elston-Ellis modification of the Scarff-Bloom-Richardson grading system on a three-grade scale. Specifically, the duct structures, size and shape of the nucleus in the tumor cells, and mitotic rate were assessed. A lesion could be of grade G1 (low grade), G2 (intermediate grade), or G3 (high grade), where a lower grade indicated a better prognosis [18]. Moreover, we evaluated tumor size stage and lymph node stage according to the TNM staging classification system. Specifically, we considered only patients with a tumor of category T1 $(<20 \mathrm{~mm})$ or T2 $(\geq 20$ or $<50 \mathrm{~mm}$ ) in terms of size and negative lymph node status (N0).

\subsection{Follow Up and Statistical Analysis}

DFS was described as the timeframe between diagnosis and locoregional/distant relapse (second invasive breast cancer, second primary cancer, and/or death without evidence of breast cancer at the date of last contact).

The age of the patient at the first tumor event was described using medians and ranges. In order to evaluate the association between each clinical feature and the sentinel lymph node status, we used the Mann-Whitney test, whereas we used Fisher's exact test for all of the other features that were measured on an ordinal and nominal scale.

DFS analyses of histological features were performed using the Kaplan-Meier method (5 and 10 years, 95\% confidence interval (CI)) and compared by the log rank test.

The Hazard Ratio (HR) for univariate analyses was calculated by the Cox proportional hazard regression model.

All statistical analyses were performed using SPSS software version 25.0 (SPSS Inc, Chicago, IL, USA).

\section{Results}

Table 1 summarizes the characteristics of the examined sample. A total of 252 patients were examined, 188 of which $(74.6 \%)$ underwent conservative surgery (quadrantectomy), while 64 patients $(25.4 \%)$ underwent mastectomy. Among patients with breast cancer dimensions of less than $20 \mathrm{~mm}$ (T1 stage), the percentage of conservative surgeries was significantly higher than that of mastectomies (respectively, $71.81 \%$ and $53.13 \%, p$-value Fisher's exact test $<0.01$ ). Moreover, $14.29 \%$ and $25 \%$ of the patients treated with conservative surgery and mastectomy, respectively, had a multifocal or multicenter tumor ( $p$-value Fisher's exact test $<0.05)$. No other significant differences were detected between the two considered groups (mastectomy vs. conservative surgery), even when the type of recurrence was considered.

No significant differences were detected in the disease-free survival (DSF) curves of mastectomy patients and conservative surgery patients ( $p$-value Log-Rank test of 0.957 ) (Figure 1). The estimated 5-year and 10-year disease-free survival probabilities were 89.9\% and $78.9 \%$, respectively, for quadrantectomy patients, whereas they were $81.3 \%$ and $79.3 \%$, respectively, for mastectomy patients. No significant differences were detected for the DFS curve differentiated by type of surgical treatment, age, or tumor histological characteristics, except for patients with tumor dimensions of between $20 \mathrm{~mm}$ and $50 \mathrm{~mm}$ and molecular sub-type Luminal B, where a significance level of $10 \%$ was considered (Table 2).

In reference to the Luminal B tumor patients, the estimated 5-year and 10-year diseasefree survival probabilities were $88.1 \%$ and $77.8 \%$, respectively, for mastectomy patients, whereas they were $58.8 \%$ (for both 5 years and 10 years) for quadrantectomy patients (Figure 2a). In reference to patients whose tumor dimensions ranged from $20 \mathrm{~mm}$ to $50 \mathrm{~mm}$, the estimated 5-year and 10-year disease-free survival probabilities were 79.2\% 
and $71.2 \%$, respectively, for quadrantectomy patients, whereas they were $83.3 \%$ and $79.7 \%$, respectively, for mastectomy patients (Figure 2b).

Table 1. Characteristics of the total collected data $(n=252)$ as well as separate characteristics of patients treated with BCS $(n=188)$ and mastectomy $(n=68)$.

\begin{tabular}{|c|c|c|c|c|c|c|c|}
\hline & & BCS $(n=188)$ & $(\%)$ & Mastectomy $(n=64)$ & $(\%)$ & Total $(n=252)$ & $(\%)$ \\
\hline \multirow[t]{4}{*}{ Age at diagnosis } & Mean (IC 95\%) & $54(52-56)$ & & $54(52-57)$ & & $54(52-55)$ & \\
\hline & $\leq 54$ & 108 & 57.4 & 31 & 48.4 & 113 & 44.8 \\
\hline & $>54$ & 80 & 42.5 & 33 & 51.6 & 139 & 55.2 \\
\hline & Total & 188 & 100.00 & 64 & 100.00 & 252 & 100.00 \\
\hline \multirow[t]{3}{*}{ ER } & Neg & 56 & 30.11 & 21 & 33.87 & 77 & 31.05 \\
\hline & Pos & 130 & 69.89 & 41 & 66.13 & 171 & 68.95 \\
\hline & Total & 186 & 100.00 & 62 & 100.00 & 248 & 100.00 \\
\hline \multirow[t]{3}{*}{ PgR } & $\mathrm{Neg}$ & 62 & 33.51 & 25 & 40.32 & 87 & 35.22 \\
\hline & Pos & 123 & 66.49 & 37 & 59.68 & 160 & 64.78 \\
\hline & Total & 185 & 100.00 & 62 & 100.00 & 247 & 100.00 \\
\hline \multirow[t]{3}{*}{$\mathrm{Ki67}(\geq 20 \%)$} & Low & 86 & 45.74 & 27 & 42.19 & 113 & 45.56 \\
\hline & High & 98 & 52.13 & 37 & 57.81 & 135 & 54.44 \\
\hline & Total & 188 & 100.00 & 64 & 100.00 & 248 & 100.00 \\
\hline \multirow[t]{3}{*}{ HER2 } & Neg & 136 & 85.53 & 48 & 84.21 & 184 & 85.19 \\
\hline & Pos & 23 & 14.47 & 9 & 15.79 & 32 & 14.81 \\
\hline & Total & 159 & 100.00 & 57 & 100.00 & 216 & 100.00 \\
\hline \multirow[t]{5}{*}{ Molecular subtype } & Luminal A & 76 & 44.19 & 20 & 32.79 & 96 & 41.20 \\
\hline & Luminal B & 42 & 24.42 & 17 & 27.87 & 59 & 25.32 \\
\hline & HER2 pos & 23 & 13.37 & 15 & 24.59 & 38 & 16.31 \\
\hline & Triple negtive & 31 & 18.02 & 9 & 14.75 & 40 & 17.17 \\
\hline & Total & 172 & 100.00 & 61 & 100.00 & 233 & 100.00 \\
\hline \multirow[t]{3}{*}{ Histological Diagnosis } & Ductal & 168 & 89.36 & 53 & 82.81 & 221 & 87.70 \\
\hline & Other & 20 & 10.64 & 11 & 17.19 & 31 & 12.3 \\
\hline & Total & 188 & 100.00 & 64 & 100.00 & 252 & 100.00 \\
\hline \multirow[t]{3}{*}{ Tumor size $* *$} & $\mathrm{~T} 1$ & 135 & 71.81 & 34 & 53.13 & 169 & 67.06 \\
\hline & $\mathrm{T} 2$ & 53 & 28.19 & 30 & 46.88 & 83 & 32.94 \\
\hline & Total & 188 & 100.00 & 64 & 100.00 & 252 & 100.00 \\
\hline \multirow[t]{4}{*}{ Grading } & G1 & 25 & 14.04 & 6 & 10.17 & 31 & 13.08 \\
\hline & $\mathrm{G} 2$ & 79 & 44.38 & 30 & 50.85 & 109 & 45.99 \\
\hline & G3 & 74 & 41.57 & 23 & 38.98 & 97 & 40.93 \\
\hline & Total & 178 & 100.00 & 59 & 100.00 & 237 & 100.00 \\
\hline \multirow[t]{3}{*}{ Multiplicity/Multifocality * } & No & 156 & 85.71 & 45 & 75.00 & 201 & 83.06 \\
\hline & Yes & 26 & 14.29 & 15 & 25.00 & 41 & 16.94 \\
\hline & Total & 182 & 100.00 & 60 & 100.00 & 242 & 100.00 \\
\hline \multirow[t]{3}{*}{ DCIS } & Absent & 127 & 75.60 & 32 & 60.38 & 159 & 71.95 \\
\hline & Present & 41 & 24.40 & 21 & 39.62 & 62 & 28.05 \\
\hline & Total & 168 & 100.00 & 53 & 100.00 & 221 & 100.00 \\
\hline \multirow[t]{3}{*}{ Type of shooting } & Locoregional & 20 & 33.33 & 3 & 15.79 & 23 & 29.11 \\
\hline & Other & 40 & 66.67 & 16 & 84.21 & 56 & 70.89 \\
\hline & Total & 60 & 100.00 & 19 & 100.00 & 79 & 100.00 \\
\hline
\end{tabular}




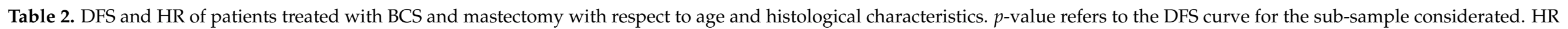

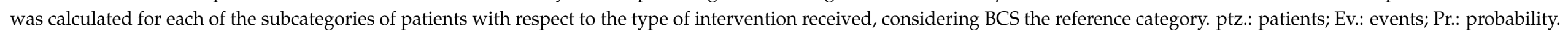

\begin{tabular}{|c|c|c|c|c|c|c|c|c|c|c|c|c|c|c|}
\hline & & & & $\mathrm{BC}$ & & & & & Mastect & & & & & \\
\hline & & & & 5 Year DFS & & 10 Year DFS & & & 5 Year DFS & & 10 Year DFS & $p$-Value & HR & $p$-Value \\
\hline & & ptz. & Ev. & Pr. $(95 \%$ CI) & Ev. & Pr. $(95 \%$ CI) & ptz. & Ev. & Pr. $(95 \%$ CI) & Ev. & Pr. $(95 \%$ CI $)$ & & & \\
\hline $\begin{array}{l}\text { Age at } \\
\text { disease }\end{array}$ & $\leq 54$ & 108 & 18 & $83.3(74.9-89.8)$ & 34 & $68.1(85.9-77.1)$ & 31 & 7 & 77.4 (58.9-90.4) & 9 & $69.3(48.6-83.3)$ & 0.678 & $1.147(0.594 ; 2.214)$ & 0.683 \\
\hline & $>54$ & 80 & 7 & $91.3(82.8-96.4)$ & 10 & $87.1(78.2-93.8)$ & 33 & 5 & 84.8 (64.5-93.0) & 7 & $77.5(61.1-91.0)$ & 0.252 & $0.598(0.244 ; 1.466)$ & 0.261 \\
\hline $\begin{array}{l}\text { Molecular } \\
\text { subtype }\end{array}$ & Luminal A & 76 & 6 & $92.1(83.6-97.1)$ & 10 & $86.6(77.1-93.5)$ & 20 & 1 & 95.0 (75.1-99.9) & 3 & $83.1(62.1-96.8)$ & 0.600 & $1.391(0.401 ; 4.817)$ & 0.603 \\
\hline & Luminal B & 42 & 5 & $88.1(74.4-96.0)$ & 9 & $77.8(63.2-89.7)$ & 17 & 7 & $58.8(32.9-81.6)$ & 7 & $58.8(32.9-81.6)$ & 0.091 & $0.474(0.193 ; 1.162)$ & 0.103 \\
\hline & Triple negtive & 31 & 3 & $90.3(74.3-98.0)$ & 9 & $71.0(52.0-85.8)$ & 9 & 1 & 93.3 (51.8-99.7) & 2 & $84.8(40.0-97.2)$ & 0.522 & $1.220(0.339 ; 4.390)$ & 0.761 \\
\hline $\begin{array}{l}\text { Histogical } \\
\text { diagnosis }\end{array}$ & Ductal & 168 & 23 & $86.3(79.5-90.6)$ & 40 & $75.6(68.4-81.9)$ & 53 & 11 & $79.2(65.9-89.2)$ & 14 & $72.0(57.7-83.2)$ & 0.707 & $0.902(0.523 ; 1.557)$ & 0.902 \\
\hline & Other & 20 & 2 & $90.0(68.3-98.8)$ & 4 & $79.4(56.3-94.3)$ & 11 & 1 & 90.9 (58.7-99.8) & 2 & $80.8(39.0-94.0)$ & 0.438 & $1.971(0343 ; 11.326)$ & 0.447 \\
\hline Tumor size & $\mathrm{T} 1$ & 135 & 10 & $93.3(87.7-96.9)$ & 29 & $77.9(69.8-84.5)$ & 34 & 7 & 79.4 (62.1-91.3) & 10 & $66.9(49.5-82.6)$ & 0.187 & $0.649(0.338 ; 1.248)$ & 0.195 \\
\hline & $\mathrm{T} 2$ & 53 & 11 & $79.2(65.9-89.2)$ & 15 & $71.5(57.7-83.2)$ & 30 & 5 & $83.3(65.3-94.4)$ & 6 & $79.7(61.4-92.3)$ & 0.099 & $2.012(0.856 ; 4.725)$ & 0.109 \\
\hline Grading & G1 & 25 & 0 & $100(86.9-100)$ & 1 & 95.8 (76.7-99.9) & 6 & 0 & $100(54.1-100)$ & 1 & $83.3(35.9-99.6)$ & 0.735 & $0.668(0.077 ; 6.156)$ & 0.738 \\
\hline & G2 & 79 & 9 & $88.6(79.5-94.7)$ & 17 & $77.9(66.4-85.9)$ & 30 & 6 & $80.0(61.4-92.3)$ & 9 & $65.9(47.2-82.7)$ & 0.167 & $0.599(0.285 ; 1.259)$ & 0.176 \\
\hline & G3 & 74 & 14 & $81.1(86.7-98.5)$ & 23 & $68.1(55.7-78.0)$ & 23 & 6 & $73.9(51.6-89.8)$ & 6 & $73.9(51.6-89.8)$ & 0.476 & $1.368(0.568 ; 3.298)$ & 0.485 \\
\hline & Yes & 26 & 3 & $88.5(69.9-97.6)$ & 6 & $76.6(52.2-88.4)$ & 15 & 5 & $66.7(38.4-88.2)$ & 7 & $51.9(26.6-78.7)$ & 0.123 & $0.449(0.156 ; 1.297)$ & 0.139 \\
\hline DCIS & Absent & 127 & 16 & $87.4(80.4-92.6)$ & 27 & $78.4(70.6-85.5)$ & 32 & 3 & $90.6(75.0-98.0)$ & 5 & $83.4(67.2-97.7)$ & 0.402 & $1.408(0.624 ; 3.176)$ & 0.410 \\
\hline & Present & 41 & 5 & $82.9(67.9-92.9)$ & 11 & $61.5(44.5-75.8)$ & 21 & 5 & $66.7(43.0-85.4)$ & 5 & $66.7(43.0-85.4)$ & 0.940 & $0.829(0.354 ; 1.941)$ & 0.666 \\
\hline $\begin{array}{c}\text { Type of } \\
\text { shooting }\end{array}$ & Locoregional & 20 & 5 & 95.9 (75.1-99.9) & 13 & $90.9(68.3-98.8)$ & 3 & 2 & $95.8(30.0-100)$ & 2 & $95.8(30.0-100)$ & 0.151 & $2.363(0.702 ; 7.954)$ & 0.165 \\
\hline & Other & 40 & 20 & $88.1(73.2-95.8)$ & 32 & $80.6(64.4-91.0)$ & 42 & 10 & 83.6 (68.6-93.0) & 14 & $75.4(34.7-93.3)$ & 0.563 & $0.844(0471 ; 1.511)$ & 0.567 \\
\hline
\end{tabular}




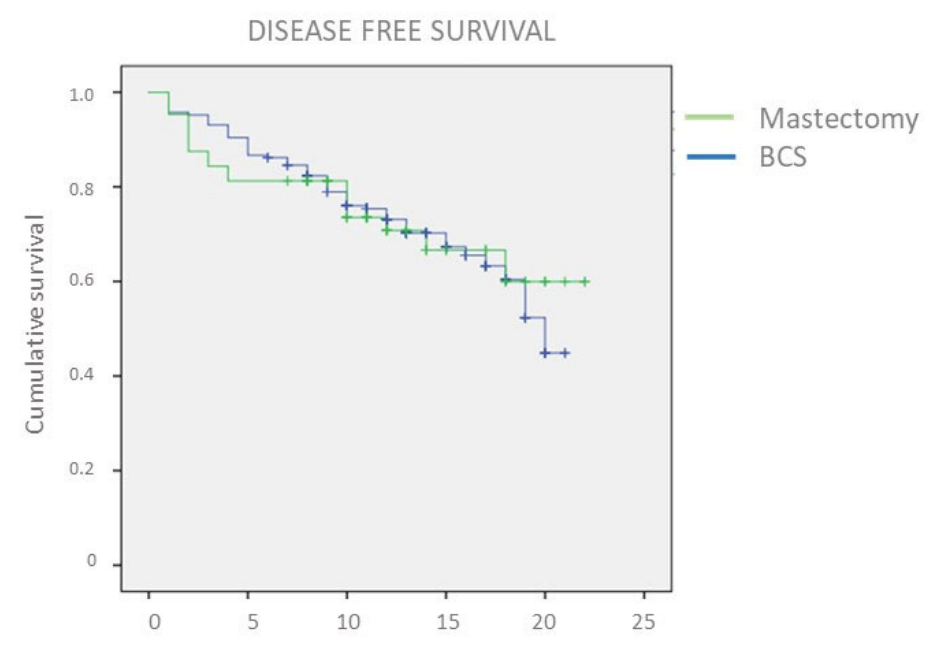

Figure 1. Disease-free survival curve according to type of surgical treatment received.

(a) DISEASE FREE SURVIVAL

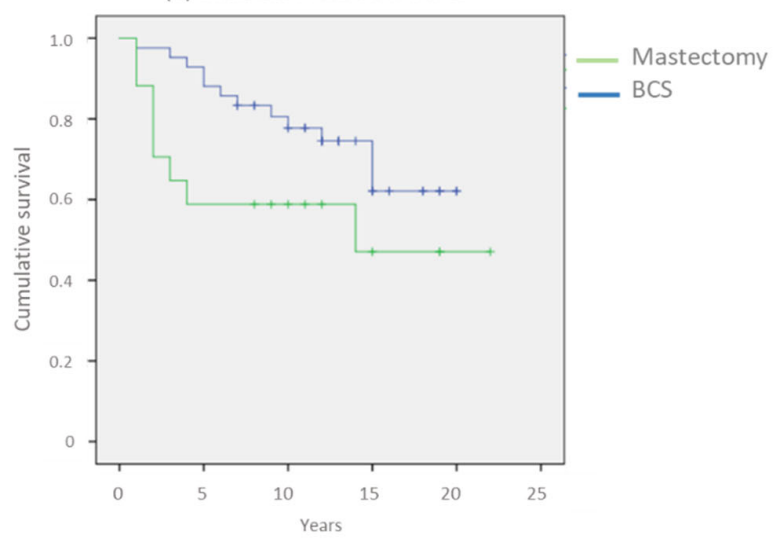

(b) DISEASE FREE SURVIVAL

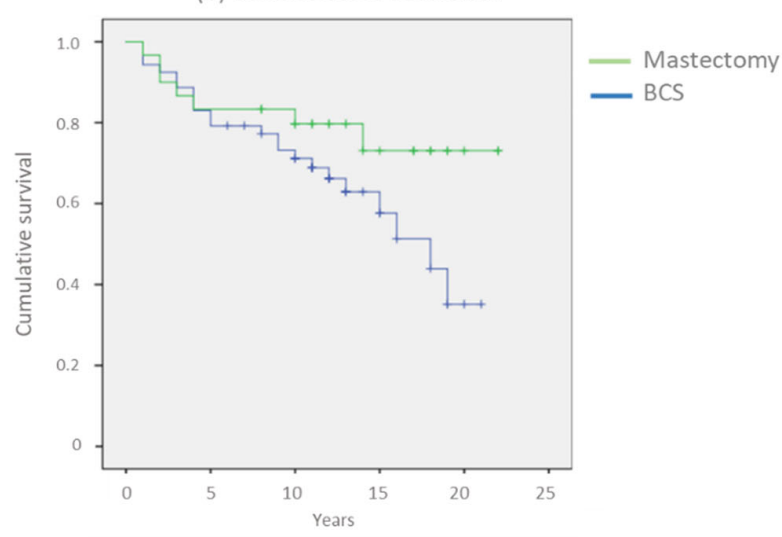

Figure 2. Disease-free survival curve for patients with Luminal B tumor type (a) or a tumor size between $20 \mathrm{~mm}$ and $50 \mathrm{~mm}$ (b) according to type of surgery received.

There were no significant differences in survival curves for BCS patients and mastectomy patients in each of the considered histological characteristics subgroups. No differences were detected even when the patient's age at first diagnosis was considered (Table 2). The only exception was for tumor dimensions ranging from $20 \mathrm{~mm}$ to $50 \mathrm{~mm}$ as well as for Luminal B tumors. In these cases, a significant difference close to the acceptable threshold of $10 \%$ was detected ( $p$-values of 0.109 and 0.103 , respectively). In more detail, it seemed that in T2 tumor patients, the recurrence probability could rise by $101.2 \%$ in BCS-treated patients compared to mastectomy-treated patients $(\mathrm{HR}=2.102)$. The same probability of recurrence seemed to be reduced by $63.6 \%$ in the case of the Luminal B tumor patients $(\mathrm{HR}=0.474)$.

\section{Discussion}

The introduction of the onco-plastic approach in breast surgery by means of quadrantectomy and "conservative" mastectomy techniques [19], when possible, is an emblematic example of the need for an increasingly targeted, personalized, and multidisciplinary treatment. In fact, treatment should consider the oncological radicality, personal risk, satisfaction, and quality of life of the patients [20,21], guaranteeing as much as possible both an effective treatment in terms of oncological radicality and acceptable aesthetic results, as well as minimizing the negative psychological impact of mastectomy through skin-sparing and nipple-sparing. 
Recent large-scale studies have shown that patients treated with BCS followed by radiotherapy have had better outcomes than those treated with radical mastectomy alone $[11,16]$. Specifically, significantly better outcomes were achieved for local relapses, distant metastases, and overall survival when using the conservative approach.

From this point of view, patients with a high-risk family history or a confirmed genetic mutation deserve to be discussed separately. Although most tumors are sporadic, a noninsignificant percentage of mammary tumors $(5-10 \%)$ are, in fact, linked to hereditary factors [22]. More than 2/3 of these result from a mutation of the BRCA- 1 and 2 genes, whose presence exposes the patient to the risk of developing mammary and/or ovarian neoplasms in the course of their life in $61-79 \%$ and $11-53 \%$ of cases, respectively $[22,23]$. This is especially the case in patients with a BRCA-1 mutation, who may develop peculiarly highly aggressive triple-negative tumors (ER-/PgR-/HER2-), often with lymph node metastases at the first diagnosis and with a higher rate of long-term relapse [24-26].

Similarly, the real impact on patient survival in the case of prophylactic mastectomy is uncertain, particularly in non-sick women with mutated BRCA, although this practice reduces the possibility of disease onset in over 90\% of cases [27-30]. However, some studies have shown a significant reduction in mortality in women who have already been operated on for breast cancer [27]. These types of patients, on whom there is also an indication for the prophylactic mastectomy of both breasts, were excluded from our study, as they would have constituted a bias of the study itself.

In our experience, there are no significant differences in terms of disease-free survival between patients treated with mastectomy and those treated with BCS, particularly at 10 years, even when differentiating by age and histological characteristics. On the other hand, at 5 years, the relative difference in survival in favor of quadrantectomy $(89.9 \%$ vs. $81.3 \%)$ may be a consequence of the greater share of advanced tumors in patients who received a mastectomy and their consequent higher rate of death in the first few years after this type of treatment.

Considering a significance level of $10 \%$, a statistical difference is observed with reference to the disease-free survival of patients with Luminal B tumors and with tumor sizes between $20 \mathrm{~mm}$ and $50 \mathrm{~mm}$. In the latter case, the best result of mastectomy is achieved at 5 years, but at 10 years this could be linked to the criterion of greater surgical radicality, especially in large or multiple tumors.

We have attempted to explain the data relating to the reduced survival seen in patients with Luminal B tumors treated with mastectomy compared to those treated with quadrantectomy. This could have been due to the detection of a greater number of single bone metastases in patients with Luminal B breast cancer [31] compared to patients in the non-luminal groups, potentiated by the higher frequency of large and multicentric neoplasms present in mastectomies.

Although the locoregional recurrence seen in patients treated with mastectomy in our sample is too small to allow us to perform statistical evaluations, there does not seem to be a statistically significant difference between the patients treated with BCS and those treated with mastectomies.

Despite some limitations related to the sample size used in our study, our results are in line with those of well-known studies carried out on a larger scale. Future studies should include an analysis of overall survival by evaluating additional factors of interest and differentiating DFS between BCS patients with positive margins and a mastectomy group.

\section{Conclusions}

In our study, we found no statistically significant differences in terms of disease-free survival between patients who received mastectomy and patients treated with breast conservative surgery (BCS), even when differentiating by age and histological characteristics. A statistically significant difference was observed in patients with Luminal type B tumors and with a tumor size between $20 \mathrm{~mm}$ and $50 \mathrm{~mm}$ (T2), where a significance level of $10 \%$ was considered. The refinement of the diagnosis, which has been made possible through the 
cutting-edge techniques of fusion of images, radiomics, and artificial intelligence [32-37], could contribute to an earlier detection of neoplasms and, therefore, to a more conservative surgical approach being used.

Author Contributions: Conceptualization, A.F., D.L.F., V.L. and R.M.; Data curation, A.F., N.P. and R.M.; Formal analysis, A.F., M.C.R. and R.M.; Methodology, A.F.; Project administration, V.L.; Resources, V.L. and R.M.; Software, A.F.; Supervision, R.M.; Writing-original draft, A.F., D.L.F. and R.M.; Writing-review and editing, A.F., M.C.R., G.G., C.C., V.D.S., V.D., S.D., D.L.F., N.P., P.T., V.L. and R.M. All authors have read and agreed to the published version of the manuscript.

Funding: This research received no external funding.

Institutional Review Board Statement: The study was conducted according to the guidelines of the Declaration of Helsinki and approved by the Scientific Board of Istituto Tumori 'Giovanni Paolo II'-Bari, Italy.

Informed Consent Statement: Informed consent was obtained from all subjects involved in the study.

Data Availability Statement: Data presented in this study are available on request from the corresponding author. The data are not publicly available because they are propriety of Istituto Tumori “Giovanni Paolo II"—Bari, Italy.

Acknowledgments: This work was supported by funding from the Italian Ministry of Health “Ricerca Finalizzata 2018".

Conflicts of Interest: The authors declare no conflict of interest.

\section{References}

1. Franceschini, G.; Sanchez, A.M.; Di Leone, A.; Magno, S.; Moschella, F.; Accetta, C.; Masetti, R. New trends in breast cancer surgery: A therapeutic approach increasingly efficacy and respectful of the patient. Geka Chiryo 2015, 36, 145-152. [CrossRef]

2. Acea-Nebril, B.; Cereijo-Garea, C.; García-Novoa, A.; Varela-Lamas, C.; Builes-Ramírez, S.; Bouzón-Alejandro, A.; Mosquera-Oses, J. The role of oncoplastic breast reduction in the conservative management of breast cancer: Complications, survival, and quality of life. J. Surg. Oncol. 2017, 115, 679-686. [CrossRef]

3. Fisher, B.; Bauer, M.; Margolese, R.; Poisson, R.; Pilch, Y.; Redmond, C.; Fisher, E.; Wolmark, N.; Deutsch, M.; Montague, E.; et al. Five-Year Results of a Randomized Clinical Trial Comparing Total Mastectomy and Segmental Mastectomy with or without Radiation in the Treatment of Breast Cancer. N. Engl. J. Med. 1985, 312, 665-673. [CrossRef] [PubMed]

4. Veronesi, U.; Zucali, R.; Luini, A. Local control and survival in early breast cancer: The milan trial. Int. J. Radiat. Oncol. 1986, 12, 717-720. [CrossRef]

5. Hong, N.J.L.; Wright, F.C.; Gagliardi, A.R.; Paszat, L.F. Examining the potential relationship between multidisciplinary cancer care and patient survival: An international literature review. J. Surg. Oncol. 2010, 102, 125-134. [CrossRef] [PubMed]

6. van Maaren, M.C.; de Munck, L.; de Bock, G.H.; Jobsen, J.J.; van Dalen, T.; Linn, S.C.; Poortmans, P.; A Strobbe, L.J.; Siesling, S. 10 year survival after breast-conserving surgery plus radiotherapy compared with mastectomy in early breast cancer in the Netherlands: A population-based study. Lancet Oncol. 2016, 17, 1158-1170. [CrossRef]

7. Corradini, S.; Bauerfeind, I.; Belka, C.; Braun, M.; Combs, S.E.; Eckel, R.; Harbeck, N.; Hölzel, D.; Kiechle, M.; Niyazi, M.; et al. Trends in use and outcome of postoperative radiotherapy following mastectomy: A population-based study. Radiother. Oncol. 2017, 122, 2-10. [CrossRef]

8. Hartmann-Johnsen, O.J.; Kåresen, R.; Schlichting, E.; Nygård, J.F. Survival is Better After Breast Conserving Therapy than Mastectomy for Early Stage Breast Cancer: A Registry-Based Follow-up Study of Norwegian Women Primary Operated Between 1998 and 2008. Ann. Surg. Oncol. 2015, 22, 3836-3845. [CrossRef]

9. Litière, S.; Werutsky, G.; Fentiman, I.S.; Rutgers, E.; Christiaens, M.-R.; van Limbergen, E.; Baaijens, M.H.; Bogaerts, J.; Bartelink, H. Breast conserving therapy versus mastectomy for stage I-II breast cancer: 20 year follow-up of the EORTC 10801 phase 3 randomised trial. Lancet Oncol. 2012, 13, 412-419. [CrossRef]

10. Wang, W.; Li, J.; Xing, J.; Xu, M.; Shao, Q.; Fan, T.; Guo, B.; Liu, S. Analysis of the variability among radiation oncologists in delineation of the postsurgical tumor bed based on 4D-CT. Oncotarget 2016, 7, 70516-70523. [CrossRef]

11. de Boniface, J.; Frisell, J.; Bergkvist, L.; Andersson, Y. Breast-conserving surgery followed by whole-breast irradiation offers survival benefits over mastectomy without irradiation. BJS 2018, 105, 1607-1614. [CrossRef] [PubMed]

12. Vila, J.; Gandini, S.; Gentilini, O. Overall survival according to type of surgery in young ( $\leq 40$ years) early breast cancer patients: A systematic meta-analysis comparing breast-conserving surgery versus mastectomy. Breast 2015, 24, 175-181. [CrossRef]

13. Ye, J.C.; Yan, W.; Christos, P.J.; Nori, D.; Ravi, A. Equivalent Survival With Mastectomy or Breast-conserving Surgery Plus Radiation in Young Women Aged <40 Years With Early-Stage Breast Cancer: A National Registry-based Stage-by-Stage Comparison. Clin. Breast Cancer 2015, 15, 390-397. [CrossRef] [PubMed] 
14. Zumsteg, Z.S.; Morrow, M.; Arnold, B.; Zheng, J.; Zhang, Z.; Robson, M.; Traina, T.; McCormick, B.; Powell, S.; Ho, A.Y. BreastConserving Therapy Achieves Locoregional Outcomes Comparable to Mastectomy in Women with T1-2N0 Triple-Negative Breast Cancer. Ann. Surg. Oncol. 2013, 20, 3469-3476. [CrossRef]

15. Millar, E.K.; Graham, P.H.; O’Toole, S.A.; McNeil, C.M.; Browne, L.; Morey, A.L.; Eggleton, S.; Beretov, J.; Theocharous, C.; Capp, A.; et al. Prediction of Local Recurrence, Distant Metastases, and Death After Breast-Conserving Therapy in Early-Stage Invasive Breast Cancer Using a Five-Biomarker Panel. J. Clin. Oncol. 2009, 27, 4701-4708. [CrossRef] [PubMed]

16. Corradini, S.; Reitz, D.; Pazos, M.; Schönecker, S.; Braun, M.; Harbeck, N.; Matuschek, C.; Bölke, E.; Ganswindt, U.; Alongi, F.; et al. Mastectomy or Breast-Conserving Therapy for Early Breast Cancer in Real-Life Clinical Practice: Outcome Comparison of 7565 Cases. Cancers 2019, 11, 160. [CrossRef]

17. Gradishar, W.J.; Moran, M.S.; Abraham, J.; Aft, R.; Agnese, D.; Allison, K.H.; Blair, S.L.; Burstein, H.J.; Dang, C.; Elias, A.D.; et al.

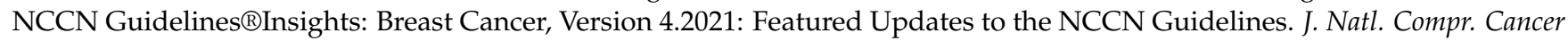
Netw. 2021, 19, 484-493.

18. Egner, J.R. AJCC Cancer Staging Manual. JAMA 2010, 304, 1726-1727. [CrossRef]

19. Galimberti, V.; Vicini, E.; Corso, G.; Morigi, C.; Fontana, S.; Sacchini, V.; Veronesi, P. Nipple-sparing and skin-sparing mastectomy: Review of aims, oncological safety and contraindications. Breast 2017, 34, S82-S84. [CrossRef]

20. Galimberti, V.; Morigi, C.; Bagnardi, V.; Corso, G.; Vicini, E.; Fontana, S.K.R.; Naninato, P.; Ratini, S.; Magnoni, F.; Toesca, A.; et al. Oncological Outcomes of Nipple-Sparing Mastectomy: A Single-Center Experience of 1989 Patients. Ann. Surg. Oncol. 2018, 25, 3849-3857. [CrossRef]

21. Mesdag, V.; Régis, C.; Tresch, E.; Chauvet, M.-P.; Boulanger, L.; Collinet, P.; Giard, S. Nipple sparing mastectomy for breast cancer is associated with high patient satisfaction and safe oncological outcomes. J. Gynecol. Obstet. Hum. Reprod. 2017, 46, 637-642. [CrossRef]

22. Armstrong, N.; Ryder, S.; Forbes, C.; Ross, J.; Quek, R.G. A systematic review of the international prevalence of BRCA mutation in breast cancer. Clin. Epidemiol. 2019, 11, 543-561. [CrossRef]

23. Kuchenbaecker, K.B.; Hopper, J.L.; Barnes, D.R.; Phillips, K.-A.; Mooij, T.M.; Roos-Blom, M.-J.; Jervis, S.; Van Leeuwen, F.E.; Milne, R.L.; Andrieu, N.; et al. Risks of Breast, Ovarian, and Contralateral Breast Cancer for BRCA1 and BRCA2 Mutation Carriers. JAMA 2017, 317, 2402-2416. [CrossRef] [PubMed]

24. Møller, P.; Stormorken, A.; Jonsrud, C.; Holmen, M.M.; Hagen, A.I.; Clark, N.; Vabø, A.; Sun, P.; Narod, S.A.; Mæhle, L. Survival of patients with BRCA1-associated breast cancer diagnosed in an MRI-based surveillance program. Breast Cancer Res. Treat. 2013, 139, 155-161. [CrossRef] [PubMed]

25. Rijnsburger, A.J.; Obdeijn, I.-M.; Kaas, R.; Tilanus-Linthorst, M.M.; Boetes, C.; Loo, C.E.; Wasser, M.N.; Bergers, E.; Kok, T.; Muller, S.H.; et al. BRCA1-Associated Breast Cancers Present Differently From BRCA2-Associated and Familial Cases: Long-Term Follow-Up of the Dutch MRISC Screening Study. J. Clin. Oncol. 2010, 28, 5265-5273. [CrossRef]

26. Dent, R.; Trudeau, M.; Pritchard, K.I.; Hanna, W.M.; Kahn, H.K.; Sawka, C.A.; Lickley, L.A.; Rawlinson, E.; Sun, P.; Narod, S.A. Triple-Negative Breast Cancer: Clinical Features and Patterns of Recurrence. Clin. Cancer Res. 2007, 13, 4429-4434. [CrossRef] [PubMed]

27. Nelson, H.D.; Pappas, M.; Cantor, A.; Haney, E.; Holmes, R. Risk Assessment, Genetic Counseling, and Genetic Testing for BRCA-Related Cancer in Women Updated Evidence Report and Systematic Review for the US Preventive Services Task Force. JAMA 2019, 322, 666-685. [CrossRef]

28. Domchek, S.M.; Friebel, T.M.; Singer, C.F.; Evans, D.G.; Lynch, H.T.; Isaacs, C.; Garber, J.E.; Neuhausen, S.L.; Matloff, E.; Eeles, R.; et al. Association of risk-reducing surgery in BRCA1 or BRCA2 mutation carriers with cancer risk and mortality. JAMA 2010, 304, 967-975. [CrossRef]

29. Heemskerk-Gerritsen, B.A.M.; Menke-Pluijmers, M.B.E.; Jager, A.; Tilanus-Linthorst, M.M.A.; Koppert, L.B.; Obdeijn, I.M.A.; van Deurzen, C.H.M.; Collée, J.M.; Seynaeve, C.; Hooning, M.J. Substantial breast cancer risk reduction and potential survival benefit after bilateral mastectomy when compared with surveillance in healthy BRCA1 and BRCA2 mutation carriers: A prospective analysis. Ann. Oncol. 2013, 24, 2029-2035. [CrossRef]

30. Hartmann, L.C.; Lindor, N.M. The Role of Risk-Reducing Surgery in Hereditary Breast and Ovarian Cancer. N. Engl. J. Med. 2016, 374, 454-468. [CrossRef]

31. Li, Z.-H.; Hu, P.-H.; Tu, J.-H.; Yu, N.-S. Luminal B breast cancer: Patterns of recurrence and clinical outcome. Oncotarget 2016, 7, 65024-65033. [CrossRef] [PubMed]

32. Basile, T.M.A.; Fanizzi, A.; Losurdo, L.; Bellotti, R.; Tangaro, S.; La Forgia, D.; Didonna, V.; Massafra, R.; Tamborra, P.; Moschetta, M.; et al. Hough transform for clustered microcalcifications detection in full-field digital mammograms. Appl. Digit. Image Process. XL 2017, 10396, 41. [CrossRef]

33. Fanizzi, A.; Basile, T.M.A.; Losurdo, L.; Bellotti, R.; Bottigli, U.; Campobasso, F.; Didonna, V.; Fausto, A.; Massafra, R.; Tagliafico, A.; et al. Ensemble DiscreteWavelet Transform and Gray-Level Co-Occurrence Matrix for Microcalcification Cluster Classification in Digital Mammography. Appl. Sci. 2019, 9, 5388. [CrossRef]

34. Fausto, A.; Bernini, M.; La Forgia, D.; Fanizzi, A.; Marcasciano, M.; Volterrani, L.; Casella, D.; Mazzei, M.A. Six-year prospective evaluation of second-look US with volume navigation for MRI-detected additional breast lesions. Eur. Radiol. 2018, 29, 1799-1808. [CrossRef] 
35. Massafra, R.; Pomarico, D.; La Forgia, D.; Bove, S.; Didonna, V.; Latorre, A.; Russo, A.O.; Lorusso, P.T.V.; Fanizzi, A. Decision support systems for the prediction of lymph node involvement in early breast cancer. Jbuon 2021, 26, $275-277$.

36. Fanizzi, A.; Pomarico, D.; Paradiso, A.; Bove, S.; Diotiaiuti, S.; Didonna, V.; Giotta, F.; La Forgia, D.; Latorre, A.; Pastena, M.; et al. Predicting of Sentinel Lymph Node Status in Breast Cancer Patients with Clinically Negative Nodes: A Validation Study. Cancers 2021, 13, 352. [CrossRef]

37. Massafra, R.; Bove, S.; Lorusso, V.; Biafora, A.; Comes, M.; Didonna, V.; Diotaiuti, S.; Fanizzi, A.; Nardone, A.; Nolasco, A.; et al. Radiomic Feature Reduction Approach to Predict Breast Cancer by Contrast-Enhanced Spectral Mammography Images. Diagn. 2021, 11, 684. [CrossRef] 